\title{
The Influence of Micro-Teaching in Enhancing Teaching Competences of Pre-Service Teachers: A Case of Saint Augustine University of Tanzania
}

\author{
Anathe R. Kimaro ${ }^{1}$, Michaela Mhagama*2, and Daniel Onyango ${ }^{2}$ \\ ${ }^{1}$ Institute of Adult Education, Tanzania \\ ${ }^{2}$ Saint Augustine University of Tanzania \\ *Corresponding Email: michaelamhagama@gmail.com
}

\begin{abstract}
The study examined the influence of micro-teaching in enhancing teaching competencies of preservice teachers at Saint Augustine University of Tanzania. The objectives of the study were to: assess teaching skills pre-service teachers acquired during micro-teaching practices, asses the perception of preservice teachers on the contributions of micro-teaching in improving their teaching skills and examine the efficacy of micro teaching in enhancing teaching competencies among pre-service teachers. The study used mixed research approach. A sample size of 140 pre-service teachers was used to generate data through questionnaire and Focus Group Discussions (FGDs). The study findings revealed that micro teaching provides an opportunity for pre-service teachers to gain basic teaching skills such as scheme of work preparation, lesson plan preparation, classroom management and motivation strategies as well as time management skills. It was also found that pre-service teachers gained some experience during micro teaching which helped them to gain insights on instructional process that may help them during the actual teaching practice. Conclusively, micro teaching is an excellent way of improving teaching competencies of pre-service teachers. It is therefore recommended that teacher educators in higher learning institutions should plan and implement micro-teaching as part of teacher training in order to improve pre-service teachers' teaching competencies.
\end{abstract}

Keywords: Micro-teaching, pre-service teacher, teaching practice, teaching competencies.

\section{Introduction}

The needs to have a professional teacher in this globalization era cannot to be overstated. This is adducible by the fact that the challenges in this globalization era are getting bigger which means a teacher should not only be an agent of knowledgetransfer but also become an agent of problem solving (Obilom, 2008). A teacher is required not only to be competent and to master the teaching and learning materials, but also to demonstrate competence in other skills in the teaching profession (Ghanaguru, Nair \& Yong, 2013). Quality of a teacher is estimated in how much the learners understand from what has been taught. To acquire professional competencies, pre-service teachers need to be well prepared before completing their teacher education program. Expounding on this notion further, Chuanjan and Chummei (2011) contend that pedagogical skills can be acquired only through a more structured and cheaper training technique by the introduction of microteaching in which pre-service teachers are exposed to teaching techniques and are allowed to practice the theoretical knowledge and skills they have acquired.

Due to the importance to prepare pre-service teachers, several scholars have considered micro teaching as one of the most effective tools in bridging the gap between theory and practice of teaching (Audu, 2010; Ghanaguru, Nair \& Yong, 2013). A considerable body of knowledge shows that micro teaching is an imperative instructional strategy that mediates between educational theory and practice (Bakir, 2014; Arsal, 2013; Anshu \& Pratibha, 2009; Alan, 2008). It aims at giving teachers confidence, support and feedback by allowing them try out among friends and colleagues a short segment of what they plan to do with their students in the near future. According to Eze (2013), microteaching offers a lot of valuable experiences such as realistic practical teaching experienced in a 
controlled room or environment and opportunity for self-evaluation in the light of supervision, feedback and discussion.

In Tanzania, like in its East African counterpart countries, teacher education programs are persistently blamed for failing to adequately prepare pre-service teachers for facing real classroom situations and challenges (Ndunguru, 2013). Pre-service teachers reported that they experienced difficulties in translating teaching theory into practice. This phenomenon brings to the fore questions about whether micro teaching has been used effectively in bridging the gap between theory and practice of teaching (Anshu \& Pratibha, 2009; Eze, 2013; Arsal, 2013). For that reason, this study sought to examine whether or not micro teaching influences teaching competencies of preservice teachers. Specifically, the study sought to:

1. Assess the teaching skills the pre-services teachers acquire during the micro-teaching practices

2. Assess Perception of pre-service teachers on the contributions of the micro-teaching in improving their teaching skills.

3. Examine the efficacy of micro teaching in enhancing teaching competencies among preservice teachers.

\section{Literature Review}

This section presents the literature review that guided the study.

\section{The Concept of Micro-teaching}

Microteaching is one of the innovations which are used to improve teacher education. From Adeleke's (2011) point of view, microteaching is a scaled down teaching encounter. During micro teaching, the teacher trainee teaches 10 instead of 45-55 learners in a normal class, spending 5-10 instead of 40 minutes in a normal class, practices only one skill at a time instead of using many integrated skills in the normal lesson and has only one or two objectives from the content instead of having about four or five objectives for a normal lesson. There is therefore reduction in the class size, length of teaching time, task to be accomplished and skills to be employed (Obanya, 2010).

From Ismail's (2011) point of view, microteaching is a laboratory training procedure for a simplification of the complexities of teaching and learning process. Microteaching is a component skill approach to teachers' preparation and training in that without adequate acquisition of teaching skills, learning process cannot be effective. Obanya (2010) defined micro teaching concept by using two words i.e. Micro and teaching. Micro means something that is small while teaching means the art of giving instruction. When the two words are joined together, they becomes micro-teaching, which means giving instruction on a smaller scale. In agreement Peker (2009) describe micro-teaching as a system of controlled practice that makes it possible for student-teachers to concentrate on specific teaching behaviors.

Rosita and Uzuka (2013) assert that while microteaching is a teaching encounter designed to enable pre-service teachers to acquire a repertoire of skills needed for effectiveness in the classroom, it remains the most appropriate programme for imparting specific skills. It employs real teaching situation for developing skills and helps one to get deeper knowledge regarding the art of teaching with a significant reduction in the teaching complexities with respect to number of students in a class, scope of content and time frame (Adeleke, 2011). Peker (2009) further asserts that micro teaching allows pre-service teachers to isolate and practice a specific skill or one technique under optimum conditions. Most of the pre-service teacher education programs widely use microteaching which is a proven method to attain gross improvement in the instructional experiences. As an innovative method of equipping teachers to be effective, skills and practices of microteaching need to be implemented (Obanya, 2010).

Furthermore, Sajed and Zaid (2012) view micro teaching as a program that prepares teacher trainees for the main teaching practice; hence it is an indispensable course for teacher trainees. This is because they need to observe and acquire appropriate knowledge and skills for teaching tasks. In the same vein, Singh (2011) considers micro teaching as the ultimate session where the preservice teachers put theories into practice.

\section{Historical Background of Microteaching}

All human endeavors are traceable to their origins. Historically, development of micro teaching started from demonstration lessons. For example, Singh (2011) denotes that in 1950s and 1960s, there was low, poor and unsatisfactory academic performance of students in USA. Teachers were blamed for poor teaching methods while teachers claimed that they were not provided with necessary teaching and learning skills to perform and reach the societal expectations. This called for experiments on the 
experiences which could be relevant for teaching in terms of innovative teacher practice programs by educators. As a result, a series of innovations were supported by substantial funding from foundations such as Ford \& Kettering and governments.

University of Stanford group which developed microteaching was one of the beneficiaries of such financial aid. At the beginning, prior introduction of micro teaching was used. It was the immediate predecessor of microteaching at Stanford University (Audu, 2010). During the time of demonstration for teachers' training, a teacher trainee presented a lesson to a small group of fellow student teachers while the rest of the class members observed. It was this demonstration lesson that later developed and resulted into microteaching by the year 1963 .

Writing on the historical development of micro teaching, Bakir (2014) argues that the name microteaching was used for the first time at Stanford University in United States of America when an experimental project on the identification of teaching skills was in progress under the guidance and supervision of the faculty members in persons of Bush, Allen, McDonald and Acheson. The team of experts was assigned the development of testing and evaluation tools to measure the attainment of teaching experiences which would be relevant to teaching interns in an innovative teacher education program. The team launched a new laboratory experience and approach in the preparation of teachers under the auspices of the Secondary
Teacher Education Program (STEP). The program was initially referred to as 'Demonstration Teaching.' While developing the approach, those things that could make an effective teacher were identified through field activities and research work. The things identified were considered teachable, learnable and could bring desired changes in behavior. That was how the concept of 'teaching skills' evolved.

In addition, Ghanaguru et al. (2013) traced the genesis of microteaching globally to the evolution of the video technology in Germany. They recorded that microteaching was traced to the handwork of Keith Acheson, N.B. Robert and W. Allen Dwight of the Stanford University. They also agreed with Chuanjan and Chummei (2011) that the development of microteaching was boosted and supported by Ford Foundation. They documented the fact that microteaching was initially named demonstration teaching in agreement with Obilom (2008). Later, microteaching was found and recognized as an effective teacher training technique especially at the pre-service level.

Between 1970s and 1980s, microteaching like harmattan fire spread from United States of America (USA) to countries like Malaysia, United Kingdom and Australia. While microteaching was universally accepted as an indispensable strategy and a panacea for effective teachers' training in 1990s, Tanzania was not left behind.

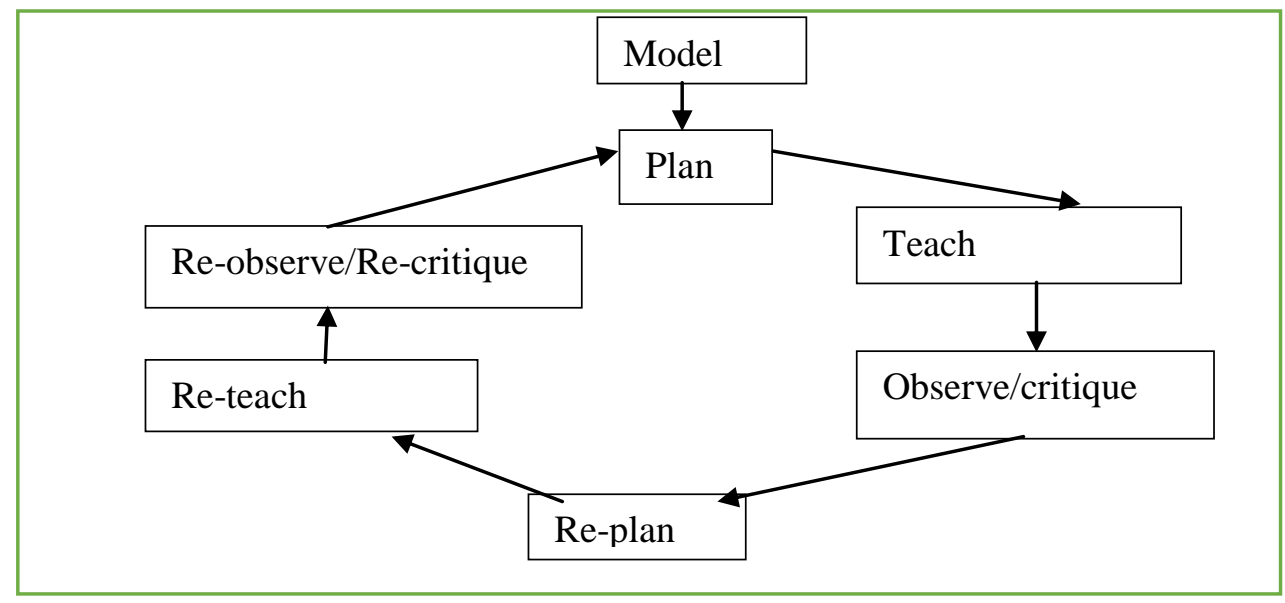

Figure 1: Microteaching Stages

\section{The Stages of Micro-Teaching}

As seen in Figure 1, basing on the micro teaching model developed (Tasdelen, Kackay and Sanli, 2009) argue that micro teaching consists of six interrelated stages. These stages are planning, teaching, observation, criticism, re-planning, re-teaching, and re-observation. As figure 1 illustrates, the cycle begins by the instructor modelling the required teaching skill scheduled for practicing by the preservice teachers. After observing the modelled skill, the pre-service teacher selects the given teaching skill and prepares a lesson plan that will enable 
him/her practice and exhibit the teacher behavior characteristic of the given skill. Emphasis of microteaching is not on the mastery of the subject matter but on the ability to exhibit the given teacher behaviors which are components of a given skill (Higgins, \& Nicholl, 2003). After planning, the preservice teachers teach the planned lesson as they are observed by a supervisor and their peers while being video recorded. At the end of the teaching encounter, the lesson is replayed for the pre-service teachers to self-critique themselves (Obilom, 2008). The student teacher's self-criticism is followed by feedback from supervisors and peers each first presenting the strengths before the weaknesses are presented.

The pre-service teacher re-plans the lesson bearing in mind the corrections and feedback received from observations of the peers, supervisor's comments and video playback. He/ She re-teach the lesson while being observed by the supervisor and his/her peers. After the teaching exercise, the lesson is reobserved and re-critiqued until the skill is mastered by the student teacher (Tasdelen, Kackay and Sanli (2009). The next teaching skill is selected and practiced accordingly following the same cycle. After the acquisition of all the essential skills, the preservice teacher is expected to be adequately prepared to integrate the skills for effective teaching in a macro teaching or in real classroom-situations.

\section{Objectives and Nature of Microteaching}

Teacher education is a significant training that is intended for teachers and teaching profession. One of the key components of teacher education program is practice. Prior teacher trainees are thrown to the normal classroom for teaching practice, they undergo microteaching to equip them with necessary teaching skills. According to Audu (2010), one of the recurring problems in teacher education is skill acquisition in teaching. The preservice teachers are exposed to rudiments of teaching through microteaching.

Writing on phases of micro teaching, Eze (2013) and Arsal (2013) identified three phases namely: knowledge acquisition phase, skill acquisition phase and transfer phase. The first phase which is knowledge acquisition phase is labelled as preactive phase. In this first phase, pre-service teachers learn about the skills and their components through lectures, tutorials, illustrations, orientation and demonstration of the skills given by the experts. They learn about the purpose of the skill and condition under which it proves useful in the teaching-learning process. They learn a lot about the skills from the demonstration given by the experts.

The second phase is the acquisition phase and is described as an interactive phase where teacher trainees are expected to plan a micro-lesson on the basis of the demonstration presented by the experts (Bakir, 2014; Chuanjan \& Chummei, 2011). The teacher trainees practice the skills through the microteaching cycle till they attain mastery level. The feedback component of microteaching contributes significantly towards the mastery level. The feedback is given on the purpose of behavioral change of the teacher trainees in the desired direction. The last phase is the transfer stage which can be referred to as the post-active phase. After attaining the mastery level and command over each of the skills, the student teacher integrates all these skills and transfers to the actual classroom teaching.

According to Ismail (2011), the major objectives of micro teaching include to enable teacher trainees to learn and assimilate new teaching skills under controlled environment or conditions. Microteaching enables pre-service teachers to master a number of teaching skills which empower them to gain confidence in teaching. One time honored adage says, 'You cannot learn to swim if you do not get in the water.' In same line of thinking, Obilom (2008) says micro teaching is geared towards equipping teacher trainees to gain confidence in teaching. This it does by making the pre-service teachers to master a number of skills in a small group of students. In addition, Higgins and Nicholl (2003) argue that microteaching aims at helping teacher trainees to gain confidence and research skills. Through microteaching, pre-service teachers can gain pre-service and in-service teaching experiences and academic self-confidence.

While microteaching is made up of some characteristics, pre-service teachers are required to use a specified teaching skill for a short time, teach a single concept and use the skill on a very small number of pupils. From Garba's (2017) perspective, microteaching is a real teaching situation where the complexity of the real classroom teaching is reduced. The reduction is done in terms of time (duration), class size (population) and content (task to be accomplished). The teacher trainees who are regarded as the micro-teachers teach between 5-10 students who are likely to be their fellow students, colleagues, classmates and friends instead of facing the real classroom situation of about 45 to 50 students. Instead of teaching for 45 to 50 minutes as 
it is in the real classroom situation, the microteachers prepare their lesson plan and teach for maximum of ten (10) minutes.

Moreover, since there is reduction in population and time, the task to be accomplished is also reduced to one or two instructional objectives. Therefore, microteaching affords the student teachers' first-hand teaching experience in the fearfree atmosphere. They practice the teaching skill in terms of definable, observable, measurable and controllable situation with repeated cycles till they attain mastery in the use of acquired skill.

\section{Different Types of Microteaching Skills and their Acquisition}

Teaching skills are the behaviors and actions that teachers acquire through practice and experiences, which are used during lesson presentation in order to make the lessons easily understandable (Obilom, 2008). As Görgen (2003) emphasizes, no teaching should actually take place without a demonstration of one skill or the other. A successful teacher in his/her teaching task might have been assisted by the instrumentality of a host of skills at his/her disposal. The unsuccessful teacher in his/her teaching tasks dissipates energy and time but still, he/she constantly meets a stone wall as the learners fail to demonstrate desired learning outcomes. $\mathrm{His} /$ her failure is not as a result of the knowledge of the subject matter but as a result of lack of skills to transmit the knowledge or impart the knowledge to his/her learners.

According to Garba (2017), teachers are more than transmitters of information like course books, information sheets and periodicals; they are facilitators in the learning process and in creating a conducive learning environment. To do this efficiently, teachers need some skills in teaching. These skills are used for training teacher trainees and they are referred to as microteaching skills. The numbers of microteaching skills depend on the authors or educators. For example, Kilic (2010) listed some of the micro teaching skills which are: writing instructional objectives, non-verbal communication, set induction, recognizing and attending to learners' behaviors, planned repetition, questioning and explanation, stimulus variation, reinforcement, chalkboard utilization and closure. In addition to the skills identified by Kilic (2010), Bakir (2014) identified other skills learnt during microteaching including chalkboard utilization, fluency in questioning, probing questions, , illustration with examples, reinforcement, learners' participation, silence and non-verbal cues as well as recognizing and attending learners' behavior and closure.

In addition, Iksan, et al. (2014), Afolabi (2010), Ambili (2013) and Ajayi (2006) identified the following microteaching skills: induction, classroom management, attending to learners' behaviors, instructional materials utilization, non-verbal communication, stimulus variation, reinforcement, and illustration with examples, questioning skills, planned repetition, participation and closure.

One of the key microteaching skills is set induction. Set induction skill is the act of introducing a lesson to awaken learners' interest in the lesson and create an atmosphere of curiosity and motivation in the class. According to Kalande (2006), set induction is a teaching skill used by a teacher to prepare learners. The teacher is a powerful agent to set the learners into the right mind so as to prepare the class for the lesson. Set induction is any method, procedure or strategy a teacher adopts at the beginning of a lesson or instructional program so as to induce learners to be very attentive for better learning and achievement of set objectives. A good beginning is most likely to bring about good ending. Set induction attracts attention of learners and prepares them mentally and physically and makes them ready to accomplish coming task.

Generally, microteaching skills can be divided into three: the pre-instructional, instructional and postinstructional. The pre-instructional skill is planning skill (writing of lesson plan and stating of objectives). Instructional skills include set induction, communication, explanation, illustration with examples, reinforcement, questioning, attending to learners' behaviors, stimulus variation, classroom management, use of chalkboard, use of instructional materials and planned repetition. Post instructional skills are closure and feedback skills.

The skill of planning is a pre-instructional skill. It is not regarded by some educationists as a teaching skill because it is not part of what actually goes on in the classroom in terms of practice or activity. Mergler and Tangen (2010) noted that, a wellplanned lesson with well stated objectives is equivalent to a lesson half completed. As a result, it is in-separable from other aspects of lesson presentation. Teachers need to realize that a wellplanned lesson serves as a frame of reference and guide in all aspects of a lesson from introduction to closure. A well written lesson plan gives confidence 
to the teacher. Many teachers fail in their teaching art right from this stage. Once the objectives of any lesson are wrongly stated, the consequence is disastrous. This is because proper statement of objectives contributes partly to making such a lesson successful. Student teachers must learn and practice the skill of planning, writing of lesson and formation of lesson objectives. They should take this aspect very seriously because it may give negative or positive first impression to the supervisor at the beginning of a lesson presentation.

Questioning skill is a very interesting skill which a teacher cannot do without for a good job to be done. It is a very important skill during microteaching. Questioning is used to draw out ideas from students. According to Kadir (2012), questioning is the skill that is used to elicit feedback, to stimulate thinking and reasoning and to develop understanding. It is used to determine students' entry behavior, personal characteristics and understanding of a given lesson. Questioning is a valuable tool for determining achievement and finding out if the set objectives of a lesson have been achieved or not.

\section{Research Methodology}

This study employed concurrent mixed research approach. This is consistent with Creswell (2009) and Dawson's (2002) argument that a mixed method research approach enhances a comprehensive and a highly deep understanding of the study variables. With regard to qualitative approach, phenomenology design was used to capture pre-service teachers' views regarding influence of micro teaching in their teaching competence. For the quantitative approach, the 'within-participants repeated measures' experimental design was used. In the 'withinparticipants repeated measures' experimental design, each of the participating pre-service teachers was involved, and was required to prepare two lesson plans for the first and second phase of micro teaching. They were to get assessed on their teaching performances in each of the two phases. The observed teaching competencies on each preservice teacher on each phase were recorded for later analysis.

The study was conducted at Saint Augustine University of Tanzania (SAUT) in Mwanza City. The basis for such a decision was the fact that the institution was strictly observing the micro-teaching theory as well as practicum which formed a major aspect of teacher-education curriculum. The $10 \%$ of the target population 1400 was used towards ensuring effective conduct of the research work. Johnson and Christensen (2017) stated that 10 percent or less could be adequately used to represent a group if it covered the characteristics of the population intended to be investigated. Hence, a total of 140 first year pre-service teachers participated in this study. They voluntarily accepted to participate in the study and were asked to fill questionnaires during the first and second phase of the micro teaching practice. A subset of 16 preservice teachers who responded to questionnaire was involved in the focus group discussion.

The questionnaire used Likert type items were required to respond on a five-point likert scale that ranged from 1 (Not at all) to 5 (Very much). Score for negatively warded statements were reversed accordingly. On average, 35 to 50 minutes were required to complete the questionnaire during regular class hours. In addition, five open-ended items were developed by the researchers based on literature review and were reviewed by peers and then were used to obtain respondents' views and opinions regarding the role of micro teaching in improving pre-service teachers' teaching skills. The Focused Group Discussions (FGDs) were carried out by the researchers and on average; each FGD had one-hour duration. Information from group discussions was intended to enrich the findings from quantitative data.

Quantitative data were generated from micro teaching practices phase one and two (pre/posttest) and closed ended questionnaire items. The data obtained from micro teaching practice was analysed using descriptive statistics through the Statistical Package for Social Sciences (SPSS) with focus on the disparity in the mean score and the standard deviation of phase one and two.

The statistical analysis to find the significance of the different results was calculated by using a scientific calculator. Subsequently, the data obtained from the closed ended questionnaire were presented in the tables. Consequently, data from the three FGDs were transcribed by the researchers and were analysed in collaboration with a research assistant. Themes were developed based on the research questions and analysis was done separately for the three FGDs. Occasionally, the researchers and the research assistant met to check for consistency. Later on, the summary of responses from the three groups were merged and reported under the 
respective research questions by using some quotations of salient voices from participants.

\section{Findings of the Study}

The findings are presented in line with the study objectives.
Teaching skills pre-service teachers acquired

Table 1 present the summary of pre-service teachers' views on teaching skills they learned by participating in micro-teaching program.

Table 1: The Teaching Skills Pre-Service Teachers Acquired During Micro Teaching

\begin{tabular}{llcc}
\hline S/N & \multicolumn{1}{c}{ Teaching Skills } & \multicolumn{2}{c}{$\mathbf{n = 1 4 0}$} \\
\cline { 3 - 4 } 1 & & 123 & \% \\
2 & Scheme of Work preparation & 122 & 87.9 \\
3 & Lesson plan preparation & 109 & 87.1 \\
4 & Motivation strategies & 96 & 77.9 \\
5 & Chalkboard usage skills & 92 & 68.6 \\
6 & Lesson presentation skills & 78 & 65.7 \\
7 & Closure skills & 69 & 55.7 \\
8 & Voice projection skills & 54 & 49.3 \\
9 & Teaching notes preparation skills & 55 & 38.6 \\
10 & Time management & 53 & 39.3 \\
11 & Reference books selection & 46 & 37.9 \\
12 & Lesson introduction skills & 45 & 32.9 \\
\hline
\end{tabular}

Data from the Table 1 shows that micro-teaching provide avenue for pre-service teachers to acquire skills on: scheme of work preparation 123(87.9\%), lesson plan preparation $122(87.1 \%)$, classroom management skills $109(77.9 \%)$ and motivation strategies $96(68.6 \%)$. Further analysis of the data in the table shows that less rated teaching skills by pre-service teachers include: closure skills 69(49.3\%), teaching notes preparation skills 55(39.3\%), time management skills 53(37.9\%) and lesson introduction skills 45(32.1\%). This implies that by participating in micro teaching, pre-service teachers can learn different teaching skills. The finding from questionnaire corroborated with the FGDs findings from pre-service teachers. During FGDs, one pre-service teacher noted that: "Frankly speaking...micro-teaching provides an opportunity for teacher trainees to learn various teaching skills. For example, we learn how to prepare lesson plan and scheme... how to management class and how to prepare teaching aids."

Another teacher trainee described teaching skills she had learned by participating in micro-teaching as follows: "After participating in micro-teaching, now I am confident that I can select teaching strategies that suit content and my students' ability...I can now employ most effective classroom management strategies and assess learning."

Responding to same question on teaching skills preservice teachers acquired by participating in micro- teaching, the micro-teaching coordinator had this to say:

Micro teaching helps pre-service teachers to know how to prepare the scheme of work, the lesson plan and the lesson notes. We also teach them classroom management skills, motivation strategies and how to use the blackboard effectively. Above all, we help them to learn how to prepare teaching aids and how to introduce and present the lesson.

These findings imply that through micro teaching, pre-service teachers acquire various teaching skills necessary for teaching. These study findings concur with Audu (2010) who identified twelve (12) microteaching skills which pre-service teachers learn. These are: set induction, classroom management, attending to learners' behaviors, instructional materials utilization, closure, communication, stimulus variation, reinforcement, repetition, examples, explanation and questioning skills. In the same vein, Bakir (2014) enumerated some microteaching skills namely: classroom management and chalkboard utilization, probing questioning, explanation, stimulus variation, illustration with examples and reinforcement.

\section{Perception of Pre-service Teachers on the Contribution of Micro-teaching}

Table 2 presents the summary of the pre-service teachers' perception on the contribution of microteaching in improving teaching skills. 
Table 2: Perception of pre-service teachers on the contribution of micro-teaching

\begin{tabular}{|c|c|c|c|c|c|c|c|c|c|c|c|}
\hline \multirow[t]{2}{*}{$\mathrm{S} / \mathrm{N}$} & & \multicolumn{2}{|c|}{1} & \multicolumn{2}{|c|}{2} & \multicolumn{2}{|c|}{3} & \multicolumn{2}{|c|}{4} & \multicolumn{2}{|c|}{5} \\
\hline & & $\mathrm{F}$ & $\%$ & $\mathrm{~F}$ & $\%$ & $\mathrm{~F}$ & $\%$ & $\mathrm{~F}$ & $\%$ & $\mathrm{~F}$ & $\%$ \\
\hline 1 & $\begin{array}{l}\text { Micro teaching has } \\
\text { boosted my teaching } \\
\text { confidence }\end{array}$ & 22 & 15.5 & 5 & 3.5 & 5 & 3.5 & 24 & 16.9 & 86 & 60.6 \\
\hline 2 & $\begin{array}{l}\text { Micro teaching has } \\
\text { improved my } \\
\text { classroom management } \\
\text { skills }\end{array}$ & 26 & 18.3 & 11 & 7.7 & 4 & 2.8 & 41 & 28.9 & 60 & 42.3 \\
\hline 3 & $\begin{array}{l}\text { My micro teaching has } \\
\text { improved my } \\
\text { chalkboard skills }\end{array}$ & 28 & 19.7 & 12 & 8.5 & 5 & 3.5 & 30 & 21.5 & 67 & 47.5 \\
\hline 5 & $\begin{array}{l}\text { Micro teaching has } \\
\text { helped me to improve } \\
\text { communication skills }\end{array}$ & 18 & 12.7 & 14 & 9.9 & 8 & 5.6 & 47 & 33.3 & 55 & 38.7 \\
\hline 6 & $\begin{array}{l}\text { Micro teaching has } \\
\text { improved my lesson } \\
\text { plan skills }\end{array}$ & 12 & 8.5 & 4 & 2.8 & 6 & 4.2 & 72 & 50.7 & 48 & 33.8 \\
\hline 7 & $\begin{array}{l}\text { Micro teaching has } \\
\text { improved my teaching } \\
\text { awareness and } \\
\text { strategies }\end{array}$ & 19 & 13.5 & 7 & 5 & 12 & 8.5 & 32 & 22.8 & 70 & 50 \\
\hline
\end{tabular}

Key: 1=Not at all, 2=Very little, 3= Little, 4=Much, 5=Very much; F-Frequency

Data in the table 2 shows that majority of the preservice teachers $86(60.6 \%)$ very much agreed with the notion that micro teaching had boosted their teaching confidence. Next a considerable number of pre-service teachers either much agreed $41(28.9 \%)$ or very much agreed $60(42.3 \%)$ with the notion that micro teaching had improved their classroom management skills and blackboard usage skills. This implies that micro teaching does not only help preservice teachers to develop and master important classroom management skills but also assists them to learn how to use the blackboard effectively. Further, analysis also showed that a considerable number of pre-service teachers perceived that micro teaching helps them to improve teaching awareness and strategies as indicated by $32(22.8 \%)$ and $70(50 \%)$ respondents who said much and very much respectively.

Questionnaire findings were corroborated with the FGDs findings from the pre-service students. All participants who participated in the FGDs acknowledged that micro teaching program was an important course since it exposed them to actual teaching experience. They noted that they benefited from feedbacks given by their mentors and also from their fellow students. These feedbacks enabled them to be aware of the 'so called' effective teaching strategies. For instance, one pre-service teacher narrated that:
Frankly speaking....during micro-teaching...I received some criticism and very useful feedbacks from my mentors and peers....Especially for chalkboard skills, it sounded like a really simple thing but it gave a big impact for me since it's a fact that how we managed our way of writing on the whiteboard was a crucial thing for students' understanding.

Likewise, another pre-service teacher said that micro teaching helped him to identify his strengths and weaknesses. He emphasized that microteaching was useful as it enabled them to detect the mistakes in his teaching. The criticisms given by the mentors and fellow student teachers were constructive to reflect on in his teaching. Those feedbacks enabled him to minimize his mistakes in the second phase of micro teaching. He also added that, by observing his peers' classroom performance, he got insights on 'effective' teaching strategies. He, for example said:

I can also say, during Micro-teaching I had a chance to watch my fellow pre-service teachers' performance and this gave me opportunity to compare them with mine. So, I learned new teaching styles and got some of their creative activities as they presenting their lesson.

\section{East African Journal of Education and Social Sciences (EAJESS) 2(1)11-22}


During FGDs, participants also reported that the experience they got from microteaching helped them to improve their communication skills. For example, one pre-service teacher narrated that:

Micro-teaching has been beneficial in preparing me to communicate properly. It made me more aware of the words that I should use in the classroom. For example, in phase one, I was assigned to teach my fellow students geography lesson... when I was teaching I did not notice that I was using the word "and so on" and "eeee" quite a lot during my micro-teaching class. During reflection, it is when my mentor said I should not do it; it would make my students distrust and also they may think that I am not competent It was really useful for me to avoid these words in my subsequent teaching practicum and in my teaching profession.

In addition, participants said that the experience they got from the micro teaching helped them to learn how to communicate or adjust language based on the level of their students. It gave them the knowledge on how they should interact and build a good relationship with students in different levels or grades. The teacher could build communication with students by adding some humors to teaching. This knowledge was indeed important in the subsequent teaching practice and teaching profession in general. In this regard, one participant narrated:

.... In communication with the students, the teachers should not be awkward. We should add some humor to attract their attention to engage them in the teaching and learning process. Also when there were some of my students that did not care from my teaching, I could call their names to answer the question related to the materials in order to make them pay attention.

Furthermore, they agreed that micro-teaching helped them to increase their confidence level. In this regard, one pre-service teacher noted: "I became more confident during the second phase of the micro teaching because of the comments and feedback I received in the first phase. So it could reduce my nervousness..."

This was also supported by another pre-service teacher who believed that micro teaching helped her to develop self-confidence that she was able to speak up in the classroom. She mentioned,
I knew that during micro-teaching class I was needed to teach and speak in front of my fellow students. So I was required to speak, learned the materials and taught how to stand up in front of the class. So it taught me to be more confident. So through prior teaching practicum, I already knew how to prepare my lesson plan, scheme of work, teaching materials and above all, how to stand up and speak in front of the students. So it has really helped me to boost my confidence.

The pre-service teachers believed that microteaching gave them an opportunity to improve their self-confidence.

With regard to chalkboard utilization skills, they emphasized that what they had learnt in microteaching class would help them in the actual teaching practicum. One pre-service teacher, for instance narrated that:

One of the benefits I have gained in these two phases of micro teaching in this university is how to use the board...I remember when I was teaching my fellow students during micro-teaching I could not control my class while I was writing on the blackboard and sometimes I blocked them to see what I was writing...but now I have learned some ways on how to write on board which was really useful when I did the second presentation. Just like how to write on the board in a proper way, for example now I can write on the whiteboard without blocking my students. So, at the same time, I could control the students when I write on the board.

Participants in the FGDs also said that micro teaching had helped them to learn to improve their questioning skills, which would be very useful during teaching practicum. During FGDs, for example, one pre-service teacher had this to say "I have learnt how to ask questions during microteaching, which I think will help me in coming teaching practice." This notion was also voiced by another pre-service teacher as she said:

During my lesson, some of the students were silent during the discussion session in the class...to make them active and participate in the discussion, I asked them some questions. 
The aim was to help them to get out of their silence and be part of the class...

From the foregoing, one can draw the fact that preservice teachers perceived micro teaching to have given them sufficient preparation for their teaching practice and teaching profession in general. The micro teaching practice helped them improve their teaching strategies, enhanced their communication skills, boosted their confidence; increased their questioning skills; improved chalkboard skills and developed the student-teachers' reinforcement skill. This study finding concurs with previous studies on similar issues. For example, studies by Peker (2009) and Rosita and Uzuka (2013) found that micro teaching helped teacher trainees gain pedagogical knowledge and thus let them improve their teaching competence. Similarly, Sajed \& Zaid (2012), Adeleke (2011) and Singh (2011) showed that micro teaching helps pre-service teachers improve their confidence through the fact that they are required to teach at least twice or thrice during the micro-teaching course. According to Mergler and Tangen (2010), micro teaching enables teacher trainees to engage in transformational learning. The pre-service teachers can boost their confidence through repetition of teaching practices.

In the same vein, Ajayi (2006) argued that microteaching gives chances for pre-service teachers to be aware of their teaching strategies through mentors' and peers' feedbacks. Kalande (2006) denotes that feedback is indeed a central part in any professional development activity. He argued that in fact, through feedback, professional competence will be developed. This was evident in this study through mentors' and peers' feedback which helped pre-service teachers shape their professional competence. In addition, mentors' feedback on better ways of communicating helped pre-service teachers to develop reinforcement skills such as the ability to reinforce students' work. Reinforcement skills are indeed important in the instructional process. Ismail (2011) opined that taking care of affective domain of the students has been one of the concerns of educational practitioners of all time. Skinner's theory for example, suggests that watching students' well-being should be the concern of all teachers (Ismail, 2011). The theory suggests that giving a high level of reinforcement for students enhances the possibility of learning success. It is very interesting to understand that the sampled teacher trainees taking the micro-teaching acquired certain level of reinforcement skills, which then shaped their professional competence prior to teaching practice in real schools.

\section{Efficacy of Micro Teaching}

To determine the efficacy of micro teaching in improving teaching competencies of pre-service teachers, observations during the first phase and second phase of micro teaching were done to see teaching competencies demonstrated by pre-service teachers. Before the observations were done, every pre-service teacher who participated in this study was requested to prepare and use his/her lesson plan in the subject of his/her specialty in both first phase and second phase of the micro teaching. Each session took 20 minutes and it was done in small groups of 20 to 25 . All sessions were observed by the researchers or research assistants by recording all the activities performed. After the first phase, pre-service teacher received feedback from both instructors and fellow students on strengths and weakness observed before going to the second phase. In each phase, pre-service teachers' performance was rated by using SAUT micro teaching assessment tools. The data from the first and second observations were analysed in terms of preparation before teaching (i.e. lesson plan, scheme of work, lesson notes, teaching aids and reference books), during teaching (i.e. lesson introduction, lesson presentation and reflection, lesson conclusion and summary as well as personality (i.e. appearance, confidence, voice projection, time and classroom management, motivation strategies, blackboard usage). The results are summarized in the table 3 .

\begin{tabular}{ccc}
\multicolumn{3}{c}{ Table 3: Mean Difference between } \\
\hline Test & Pre-test & Post-test \\
\hline Mean & 26.27 & 37.7 \\
N & 140 & 140 \\
\hline
\end{tabular}

The data in table 3 shows that micro teaching pretest mean score performance for pre-service teachers was 26.27 while, for micro teaching post test was 31.7. The difference in the mean scores performance was 11.43. From these scores, it can be seen that pre-service teachers in the second phase of micro teaching performed better than in their first phase. The reason is that after the first phase, feedback from both instructors and fellow students was given and the students also had opportunities to observe their colleagues teaching. This implies that the experience pre-service teachers gained during micro teaching helped them gain insights on improving instructional process during teaching practice. This finding concurs with 
Ambili (2013) and Obilom (2008) who found that teachers' teaching competence is developed not in a vacuum; it is shaped through context and experiences.

\section{Conclusion and Recommendations}

This section provides the conclusions of the study findings and recommendations:

\section{Conclusions}

Based on the study findings, it can be concluded that; micro teaching helped pre-service teachers acquire various teaching skills necessary for teaching profession; it is an excellent way of improving teaching competencies of pre-service teachers; and it provides the pre-service teacher with an opportunity to improve communication; questioning skills; in boosting their confidence; allowing them to be aware of their teaching strategies; chalkboard and reinforcement skills. Also, the study identified that pre-service teachers in the second phase of micro teaching performed better than in their first phase.

\section{Recommendations}

Based on the conclusions, the study recommends that:

1. Micro-teaching course should be made a compulsory subject in pre-service teacher programs.

2. Micro teaching is necessary in teacher training institutions in their attempt to produce highly qualified teachers. Therefore, teacher educators in teacher's education programme particularly higher learning institutions should plan and implement micro-teaching in the pedagogical course to improve pre-service teachers teaching competencies.

3. Professional teachers should mentor preservice teachers in both first and second phases of micro-teaching in order to improve performance of pre-service teachers.

\section{Reference}

Adeleke, O. (2011). Comparison, between traditional teaching and microteaching during school experience of student teachers question. Journal of Educational, Research, 20 (1), $1-13$.

Afolabi, A. O. (2010). The Concept of microteaching in Aleiburu, U.I. Lagos: Jinsalaam Press.
Ajayi, Y. A. (2006). An introduction to Microteaching: Ilorin: Indemac publishers.

Alan, H. (2008). The art of Teaching. Great Britain: Pearson Education Limited.

Ambili, R. (2013). Microteaching: An efficient technique for learning effective teaching. Journal of Research in Medical Sciences; 18 (2) 158-163.

Anshu, R.S. \& Pratibha, N (2009). Introducing micro teaching sessions in an Indian medical school. Medical Education, 43 (11), 1087 1088.

Arsal, Z. (2013). The effects of micro teaching on the critical thinking Disposition of preservice Teachers. Abert Izzet Baysal University, Turkey.

Audu, U.F. (2010). Micro teaching skills educational technology in practice. De new creation publishing house Ltd.

Bakır, S. (2014). The effect of microteaching on the teaching skills of preservice science teachers. Journal of Baltic Science Education, 13(6), 789-801.

Chuanjan, H, \& Chummei, Y. (2011). Exploring authenticity of microteaching in presence teacher education programme. Central china normal university Wuhan, China.

Creswell, W.K., (2009). Research Design; Quantitative and Mixed Approach.. New Delhi. Sage Publication.

Dawson, C., (2002). Practical Research Methods. New Delhi: UBS publisher distributors.

Eze, A.E. (2013). The essentials of Microteaching and Teaching Practice. Chika Educational Publishes, NSUKKA, Nigeria.

Garba, L.S. (2017). Effect of Micro-teaching Skills on Nigerian Colleges of Education Students Teaching Practice Performance in Northwest Geo-Political Zone, Nigeria (Doctoral Dissertation, Ahmadu Bello University, Zaria- Nigeria).

Ghanaguru, S., Nair, P., \& Yong, C. (2013). Teacher trainers' beliefs in Microteaching and Lesson Planning in a Teacher Training Institution. The English Teacher, 42(2).

Görgen, i. (2003). The effect of microteaching practises on student teachers' views of 
giving lessons in the classroom. Journal of Hacettepe University Education Faculty, 24, 56-63.

Higgins, A \& Nicholl, H. (2003). The experience of lecturers and students in the use of micro teaching as a teaching strategy. Nurse education in practice, $3,220-227$.

Iksan, Z. H., Mohd-Nor, S. N. A., Mahmud, S. N., \& Zakaria, E. (2014). Model of Lesson Study Approach during Micro teaching. International Education Studies; Vol. 7, 102119.

Ismail, A. (2011). Student Teachers" Microteaching Experience in a Preservice English Teacher Education Program. Journal of language Teaching and Research 2(5) 1043-1051.

Johnson, B. \& Christensen, L (2017). Educational research: Quantitative, qualitative and mixed approaches. California: SAGE Publications Inc.

Kadir, B. (2012). Effect of microteaching technique on teacher candidates beliefs regarding mathematics teaching. Akdeniz University, Alenya faculty of Education, Department of Elementary Education. Alanya, Turkey.

Kalande, A. (2006). The microteaching experience: student perspective. Education, 121 (4), 830 -835 .

Kilic, A. (2010). Learner-Centered Micro Teaching in Teacher Education. International Journal of Instruction, 3(1)12-27.

Mergler, A.G. \& Tangen D. (2010). Using Microteaching to Enhance Teacher Efficacy in Pre service teachers. Teaching education. 21 (2) $199-210$.

Ndunguru, U. (2013). The Contribution of Teaching Practice to Teacher Professional Competence; The Case of Morogoro and Klerruu Teacher Colleges. Unpublished Dissertation, the University of Dodoma, Tanzania.

Obanya, P. (2010). Bringing Back the Teacher to the African School. Addis Abade: UNESCO_ICCBA.

Obilom, J.E.C. (2008). Toward professional teacher. Journal of educational studies, university of Jos. 10(1) (166 - 176).

Peker, M. (2009). The use of expended microteaching for reducing pre-service teachers teaching anxiety about mathematics. Scientific researcher an essay. vol. 4 (9) pp 872-880.

Rosita, M, \& Uzuka, S (2013). Rational for application of microteaching to improve teaching. Journal of Educational Research 4 (2), $27-31$.

Sajed, A. \& Zaid, A. N. (2012). Pre service teachers' opinions about the micro teaching method in teaching practice classes. Turkish online Journal of Educational Technology 12 (2).

Singh T. (2011). Micro teaching revisited in National Medical Journal of India, 24:363-4.

Tasdelen, T, Kackay, A, \& Sanli, S. (2009). The effect of microteaching application on the preservice teachers' competency levels. Procedia social and behavioural sciences, 1 , $844-847$. 